\title{
Fullerene-biomolecule conjugates and their biomedicinal applications
}

\author{
This article was published in the following Dove Press journal: \\ International Journal of Nanomedicine \\ 18 December 2013 \\ Number of times this article has been viewed
}

\section{Xinlin Yang'}

Ali Ebrahimi'

Jie $\mathrm{Li}^{1,2}$

Quanjun Cui'

'Orthopaedic Research Laboratory, Department of Orthopaedic Surgery, University of Virginia School of Medicine, Charlottesville, VA, USA;

${ }^{2}$ School of Materials Science, Beijing Institute of Technology, Beijing,

People's Republic of China
Correspondence: Quanjun Cui Department of Orthopaedic Surgery, University of Virginia School of Medicine, 400 Ray C Hunt Drive, Suite 330,

Charlottesville, VA 22903, USA

$\mathrm{Tel}+$ I 4342430236

Fax +I 4342430242

Email qc4q@hscmail.mcc.virginia.edu
Abstract: Fullerenes are among the strongest antioxidants and are characterized as "radical sponges." The research on biomedicinal applications of fullerenes has achieved significant progress since the landmark publication by Friedman et al in 1993. Fullerene-biomolecule conjugates have become an important area of research during the past 2 decades. By a thorough literature search, we attempt to update the information about the synthesis of different types of fullerene-biomolecule conjugates, including fullerene-containing amino acids and peptides, oligonucleotides, sugars, and esters. Moreover, we also discuss in this review recently reported data on the biological and pharmaceutical utilities of these compounds and some other fullerene derivatives of biomedical importance. While within the fullerene-biomolecule conjugates, in which fullerene may act as both an antioxidant and a carrier, specific targeting biomolecules conjugated to fullerene will undoubtedly strengthen the delivery of functional fullerenes to sites of clinical interest.

Keywords: fullerene, amino acid, peptide, oligonucleotide, sugar, ester

\section{Introduction}

The research on $\mathrm{C}_{60}$ and its various derivatives began 3 decades ago, when Kroto et al first reported the discovery of a new allotropic form of carbon $\mathrm{C}_{60} \cdot{ }^{1}$ Since then, it has become a topic of considerable interest in medicinal chemistry due to its potential as a biologically active compound.

The landmark work in this area was published in 1993 by Friedman et al. ${ }^{2}$ With the aid of computer-based simulations, Friedman et $\mathrm{al}^{2}$ and Schinazi et $\mathrm{al}^{3}$ found that the hydrophobic cleft of the human immunodeficiency virus (HIV)-1 protease can seamlessly host a $\mathrm{C}_{60}$ molecule. Meanwhile, they provided experimental evidence that formation of the HIV-1 protease and a fullerene derivative complex led to virucidal activity through inactivation of this enzyme. ${ }^{2,3}$ This discovery was the first piece of evidence that fullerenes could have pharmaceutical significance through interactions with biological targets, highlighting the great potential of fullerenes in medicinal applications. Since fullerenes possess unique geometrical shapes, as well as novel photophysical properties, in addition to being efficient radical scavengers, a wide variety of biological applications have been considered. However, due to the $\mathrm{C}_{60}$ sphere's inability to dissolve in polar substances, most notably water, its practical applications in materials science, biotechnology, and medicine are largely limited. Therefore, water-soluble fullerene-based derivatives, especially fullerene-containing biomolecules, have been widely investigated. In order to be selectively delivered to their biological targets, fullerenes must first be conjugated with molecules possessing 
biological affinity to certain nucleic acids, proteins, cell types, organelles, etc. ${ }^{4-7}$ In this review, we will briefly summarize the different types of fullerene-biomolecule conjugates in the literature over the past 2 decades. Furthermore, results focusing on the biological and pharmaceutical utilities of these compounds, as well as some important fullerene derivatives unattached to biomolecular conjugates, will also be discussed in this review.

\section{Fullerene-containing amino acids and peptides}

\section{Antioxidants and antiapoptotic agents}

Recent studies have suggested that reactive oxygen species (ROS), such as nitric oxide (NO) and superoxide $\left(\mathrm{O}_{2}^{-}\right)$, play a key role in the metabolism processes; however, upregulated oxygen and nitric radicals have been shown to induce cellular instability through the premature triggering of cascades involved in programmed cell death. ${ }^{8}$

$\mathrm{NO}$, as a free radical, is synthesized by a family of enzymes called NO synthase (NOS) utilizing substrates from the guanidine group of L-arginine, and NO has been found to be important in maintaining the normal state of human vasculature. Despite its vital role in normal physiology, NO is also capable of combining with $\mathrm{O}_{2}{ }^{-}$molecules, leading to serious and toxic effects within cells. ${ }^{8}$

In such cases, radical sponges or inhibitors can be introduced to decrease cell death. ${ }^{9}$ The protection against the apoptotic cell death level is strictly related to the compounds' ability to react with oxygen radical species such as $\mathrm{O}_{2}^{-}$and hydroxyl radicals. Through this mechanism, sponges can prevent attacks on lipids, proteins, DNA, or other macromolecules. In particular, some fullerene-based polypeptides, such as $\mathrm{C}_{60}$-tagged poly(L-glutamic acid) 1 (Figure 1A), have been found to be dose-dependent, competitive scavenging agents against $\mathrm{O}_{2}{ }^{-} \cdot{ }^{10}$

Two nanoscale fullerene-based amino acids, fullerene $\alpha$-aspartate acid 2 (Figure 1B) and fullerene $\alpha$-glutamic acid 3 (Figure 1C), tested in our lab, also displayed the unique ability to remove oxygen free radicals in a concentration-dependent manner. Furthermore, nano-fullerene glutamic acid was shown to be a more efficient free radical scavenger than nano-fullerenes bound to aspartic acid (Yang, unpublished data, 2013).

The $\mathrm{C}_{60}$-substituted phenylalanine 4 (Figure 1D), along with its N-Boc-protected derivative and lysine derivative prepared by Yang et $\mathrm{al}^{11}$ presented similar dose-dependent antioxidant effects. Interestingly, there was a slight reduction in activity between 4 and the derived peptide 4-(Glu) $\left.)_{4}^{-(G l y)}\right)_{3}^{-}$ Ser-OH; however, this mechanism is not well understood and will require further study in the future. ${ }^{11}$

In a paper by Ioannou et al, a sulfur-containing dihydropyrrolo $\mathrm{C}_{60}$ derivative 5 (Figure 1E) was noted as being of particular interest, since its structure, in principle, could provide it with the ability to act as an antioxidant or possibly an amino acid mimic. ${ }^{12}$

Additionally, fullerene-containing peptides are expected to have strong applications in the prevention of a variety of
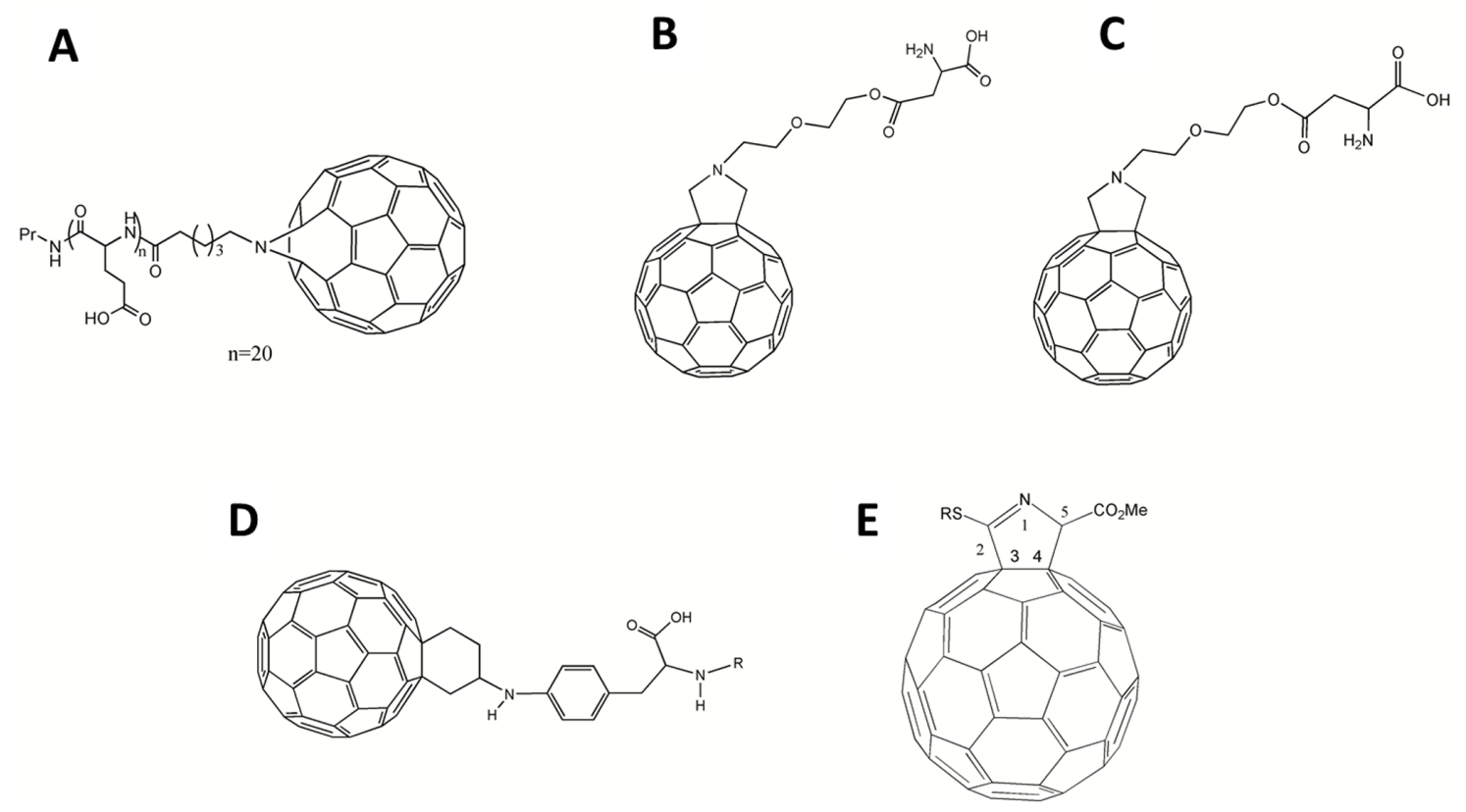

Figure I Chemical structures of antioxidative fullerene derivatives I-5.

Notes: (A) I; (B) 2; (C) 3; (D) 4; (E) 5.

Abbreviations: Pr, Propylamine group; Me, Methyl group. 
clinical abnormalities, most notably in the area of neural diseases. As reported by $\mathrm{Hu}$ et al, the protective effects of a $\beta$-alanine $\mathrm{C}_{60}$ derivative 6 (Figure $2 \mathrm{~A}$ ) ${ }^{13}$ and a cystine $\mathrm{C}_{60}$ derivative 7 (Figure $2 \mathrm{~B})^{14}$ on hydrogen peroxide-induced oxidative stress and apoptotic cell death in cultured rat pheochromocytoma (PC12) cells was detectable and without apparent toxic effects. This result may be due to fullerene-containing compounds' measurable scavenger activity toward ROS in both in vivo and in vitro testing with PC12 cells. They also reported that a $\mathrm{C}_{60}$-methionine derivative 8 (Figure 2C) was more powerful than either the $\beta$-alanine $\mathrm{C}_{60}$ derivative 6 or the cystine $\mathrm{C}_{60}$ derivative 7 in protecting human $\mathrm{SH}-\mathrm{SY} 5 \mathrm{Y}$ neuroblastoma cells from lead-induced toxicity. ${ }^{15}$

In a paper published in 2002, Cusan et al were able to synthesize a new water-soluble mono-substituted $\mathrm{C}_{60}$ derivative 9 (Figure 2D). ${ }^{16}$ However, during in vitro assay testing, the compound was shown not only to be ineffective at preventing glutamate-associated cell death, but was also found to have significant concentration-dependent toxicity. Despite failed attempts at synthesizing a neuroprotective compound, the study did yield a noteworthy conclusion: the chemical requirements for a $\mathrm{C}_{60}$ compound to elicit neuroprotective effects are based more on the number of substitutions and not necessarily on the nature of those substitutions. Cusan et al hypothesized that an increase in the number of polar groups on a fullerene compound would probably prevent its interaction with the cell membrane and prevent any disruption associated with such an interaction. As a result of this finding, the group stated that future research should focus on multiple addition products in order to guarantee better solubility with a lower degree of aggregation as opposed to monoadducts. ${ }^{16}$ In this regard, Kraszewski et al recently studied the uptake mechanism of fullerenes bearing cationic ammonium groups by membranes modeled as lipid bilayers. ${ }^{17}$ Through the use of extensive molecular dynamics simulations and free-energy calculations, they concluded that "the lipid bilayer appears to be very selective with respect to the amount of amino groups conjugated with $\mathrm{C}_{60},{ }^{\prime \prime 17}$

Basso et al synthesized a novel water-soluble fullerene derivative 10 (Figure $2 \mathrm{E}$ ) by conjugating fullerene to the $N$-methyl-D-aspartate receptor in order to develop receptorspecific therapy for treatment of central nervous system disorders. ${ }^{18}$ The fullerene derivative was demonstrated to reverse the axonal loss and disability in a mouse model of progressive multiple sclerosis. In vitro assays showed that it could protect neurons from oxidative and glutamate-induced injury and restored glutamine synthetase and glutamate transporter expression in astrocytes after suffering inflammatoryrelated insults. ${ }^{18}$

In an effort to explore novel treatment of Alzheimer's disease, Makarova et al injected hippocampal pyramidal cells with $\beta$-amyloid to mimic the pathogenesis of this disease. ${ }^{19}$ By day 14 of the study, the pyramidal cells underwent significant degradation and decreased protein synthesis, along with accumulation of amyloid within the cells. Makarova et al hypothesized that the cells underwent
A

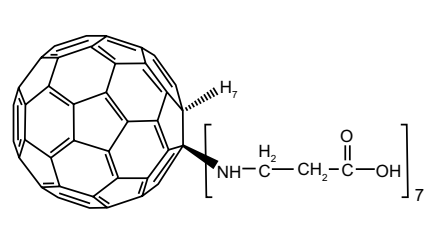

B

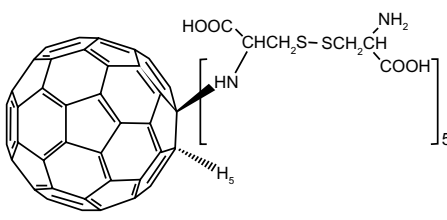

C

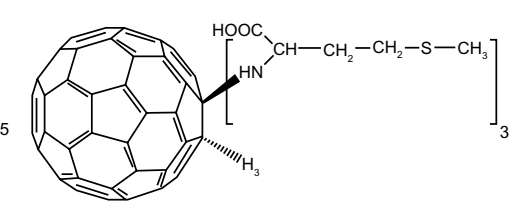

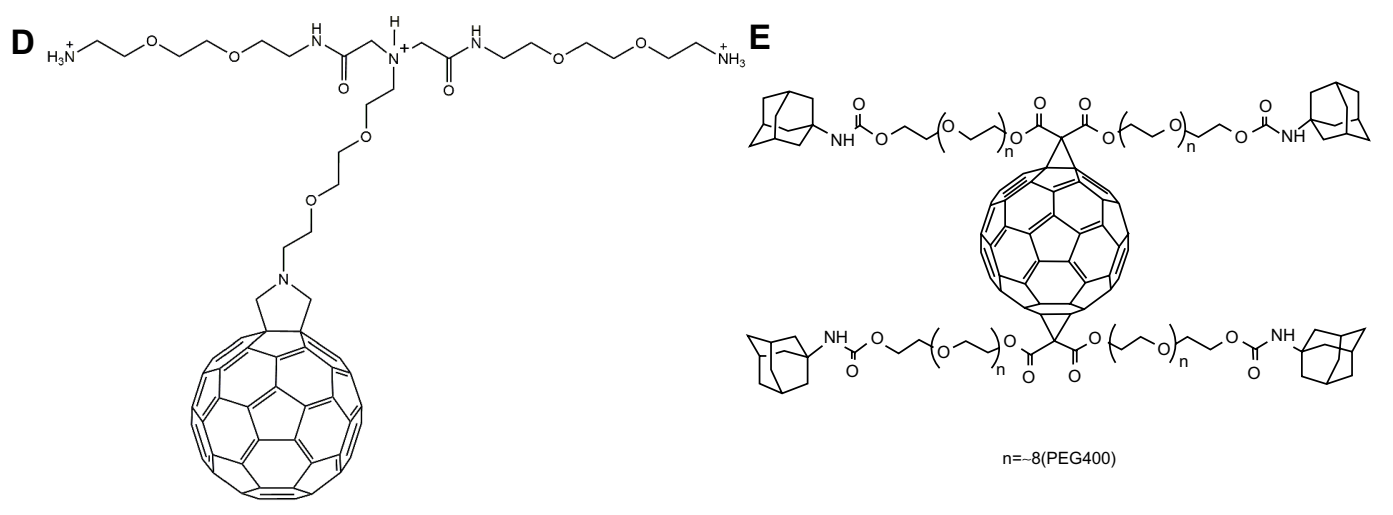

Figure 2 Chemical structures of antioxidative fullerene derivatives 6-10.

Notes: (A) 6; (B) 7; (C) 8; (D) 9; (E) 10.

Abbreviation: PEG, Polyethylene glycol. 
such changes due to increased oxidative stress, and that utilizing an aqueous colloid solution of $\mathrm{C}_{60}$ would prevent such damage. After being treated with a $\mathrm{C}_{60}$-containing solution, cells injected with the amyloid protein showed decreased amyloid aggregation and prevented disturbances in protein synthesis and neurodegeneration. The group concluded that functionalized $\mathrm{C}_{60}$ might be a good source for anti-amyloid drug therapy due to its antioxidant and anti-aggregative properties. ${ }^{19}$

Additionally, in a recent study, Fujimoto et al discovered that ROS produced by laser irradiation of the skin were suppressed by polyvinylpyrrolidone-fullerene. ${ }^{20}$ They further suggested that, due to its positive effects toward decreasing inflammation, redness, pigmentation, and other damaging side effects, fullerene-based products may have a potential role as after-care therapy following laser irradiation procedures involving the skin. ${ }^{20}$

Finally, in a previous study from our lab, we found that a polyhydroxylated fullerene, fullerol (or fullerenol) inhibited adipogenesis and simultaneously enhanced osteogenesis in the bone marrow through the elimination of ROS in models that underwent dexamethasone-induced oxidative stress. ${ }^{21}$ Fullerol has also been found, by Cai et al, to prevent mitochondrial dysfunction and oxidative damage in a cellular model of Parkinson's disease induced by 1-methyl-4phenylpyridinium. ${ }^{22}$

\section{Enzymatic interaction}

As is the case with most popular drug targets, enzyme inhibition can be a key to preventing or modifying certain disease states, and with the finding that various $\mathrm{C}_{60}$-biomolecule derivatives may possess such inhibitory characteristics, fullerenes have become a key topic of research in the field of medicinal chemistry.

The amino acid-type fullerene derivative has been found to be a potent inhibitor of the HIV-reverse transcriptase molecule. In a study by Mashino et al, the amino acid-type fullerene derivative 11 (Figure 3A) was found to be more effective than its counterpart, derivative 12 (Figure 3B), as a protease inhibitor. ${ }^{23}$ It appeared that two carboxylic acid groups at the pyrrolidine ring were necessary for effective inhibition when utilizing the amino acid structure of C60 chemical derivatives. $^{23}$

The inhibition of Taq DNA polymerase by fullerene derivatives in a polymerase chain reaction was originally reported in 2007 by our lab. ${ }^{24,25}$ Further investigation by other researchers showed that this inhibition was attributed to the interaction between the nanoparticles and the Taq DNA polymerase in the reaction. ${ }^{26-28}$ By atomistic molecular dynamics simulations, a clear tendency was uncovered for hydrogen bonding between fullerol and both the deoxynucleotide triphosphates and single-strand DNA templates involved in the reaction. ${ }^{26}$ Using a combination of molecular docking and molecular dynamics simulations, structural changes in the tip and the two $\alpha$-helices of a subdomain within the enzyme were found to be crucial for proper polymerase activity, and, upon fullerene derivative binding, prevention of the binding of DNA to protein occurred. ${ }^{27}$ Moreover, it has been demonstrated that the abundance of proteins could partially reverse the observed inhibition through competitive binding. ${ }^{28}$

The peptidic structures of fullerene-peptide conjugates have been found to be more interactive with the active or allosteric sites of enzymes in modifying their activity when compared to alternative structures, such as a spheroidal or lipophilic
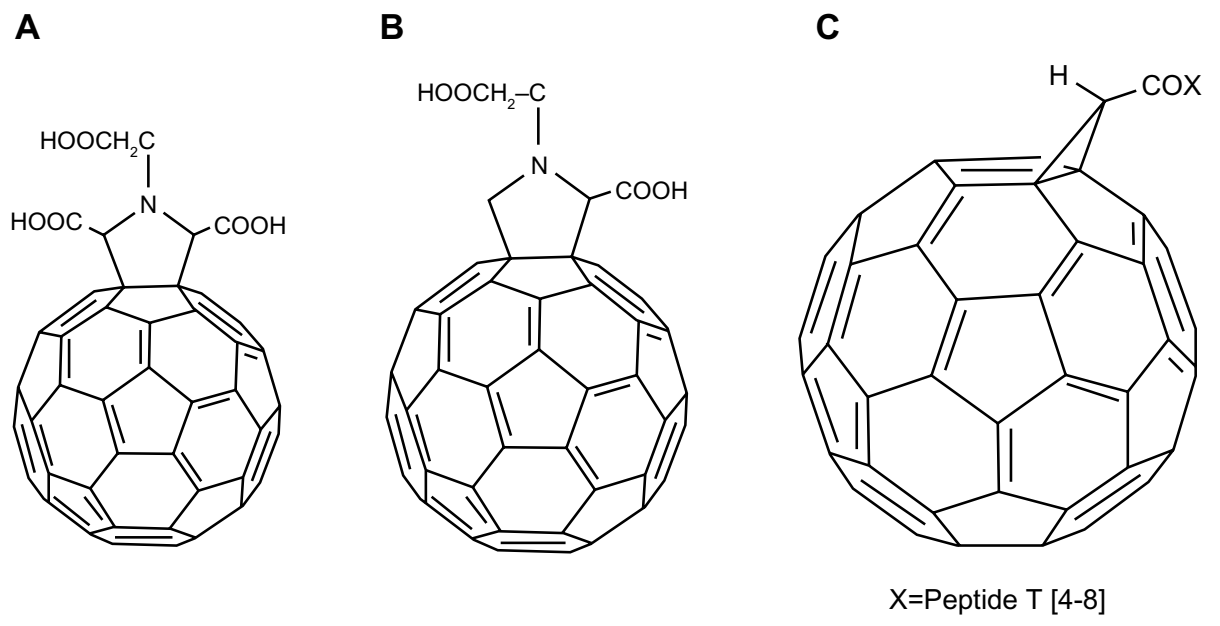

Figure 3 Chemical structures of fullerene derivatives II-I3 interacting with enzymes of the human immunodeficiency virus. Notes: (A) II; (B) 12; (C) 13. 
structure..$^{29}$ A study conducted by Toniolo et al demonstrated that the fullerene "ball" of one fullerene-peptide 13 (Figure 3C), produced as a result of covalent linking of 1,2-dihydro-1,2methanofullerene-61-carboxylic acid to an $\alpha$-amino group of the hydrophilic 4-8 sequence of peptide T, interacted, albeit weakly, with the active site of the HIV-1 protease. ${ }^{29}$

In a study by Pastorin et al, cationic bis- $N, N$ dimethylfulleropyrrolidines 14 (Figure 4A), 15 (Figure 4B), 16 (Figure 4C), and 17 (Figure 4D) were shown to be capable of noncompetitive inhibition of enzymatic activity of the acetylcholinesterase molecule (AChE) ${ }^{30}$ Molecular modeling showed that each bis-quaternary salt was docked into the active site of the enzyme, and the fullerene cage was capable of accommodating the hydrophobic cavity of the AChE molecule. This was observed due to the interaction of the ammonium groups and the side chains of key amino acid residues of the principal or peripheral binding sites. The group proposed that these new compounds could serve as potent inhibitors of the $\mathrm{AChE}$ molecule. ${ }^{30}$ Furthermore, according to a recent report by Patel et al, a cationic fullerene derivative 18 (Figure 4E), which possessed a substituted quinazolinone moiety, elicited activity against Mycobacterium tuberculosis hypoxanthine-guanine phosphoribosyltransferase enzyme. ${ }^{31}$

A

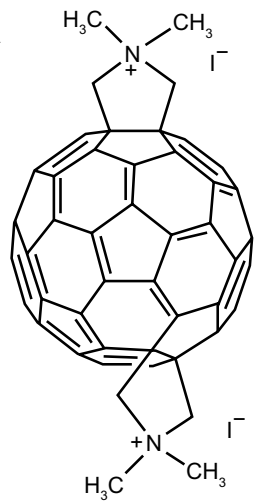

C

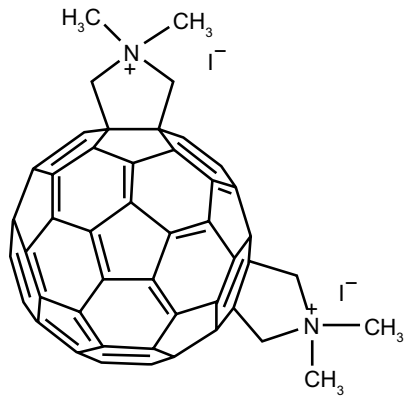

D

\section{Antiviral and antimicrobial activity}

As mentioned previously, fullerene derivatives with antiHIV activities have garnered substantial attention since the landmark paper by Friedman et al in 1993. ${ }^{2}$ Bosi et al proposed a basic approach for the functionalization of fullerene with charged amino derivatives. ${ }^{32}$ Using this method, this group was able to synthesize a series of bis-functionalized fullerene $\mathrm{C}_{60}$ derivatives in order to establish structureactivity relationship profiles and their activities against the HIV-1 and HIV-2 strains. As a result, they were able to show that the position of addends on the $\mathrm{C}_{60}$ nucleus could affect its activity; most notably, they showed that only the trans-2 isomers possessed promising activity. In addition, it was shown that a quaternary pyrrolidinium nitrogen was critical for solubility and that a longer solubilizing chain might cause higher cytotoxicity. ${ }^{32}$

The discovery of the intercalation of fullerenes into biological membranes has encouraged many research groups to study the potential for fullerenes to be utilized as antimicrobials in medical therapy.

Pantarotto et $\mathrm{al}^{33}$ and Pellarini et $\mathrm{a} \mathrm{l}^{34}$ presented a group of fullerene-peptides, called fulleropeptides, that showed great potential for bacteriostatic activity. In one study, a $\mathrm{C}_{60^{-}}$ functionalized amino acid was synthesized by conjugating

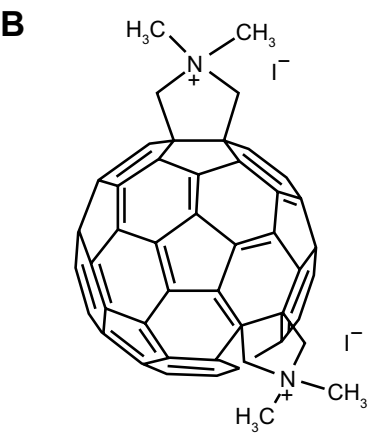

E

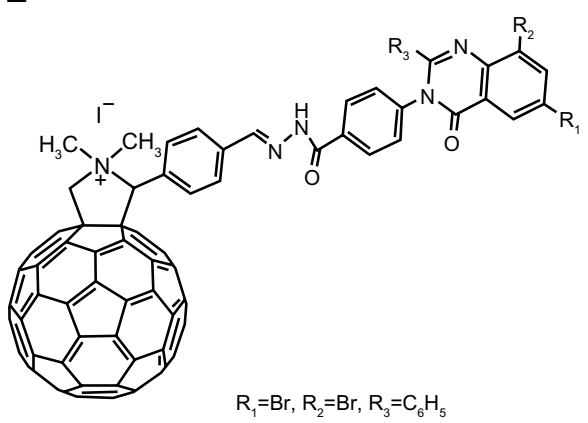

Figure 4 Chemical structures of fullerene derivatives 14-18 interacting with acetylcholinesterase or hypoxanthine-guanine phosphoribosyltransferase. Notes: (A) 14; (B) 15; (C) 16; (D) 17; (E) 18. 
A

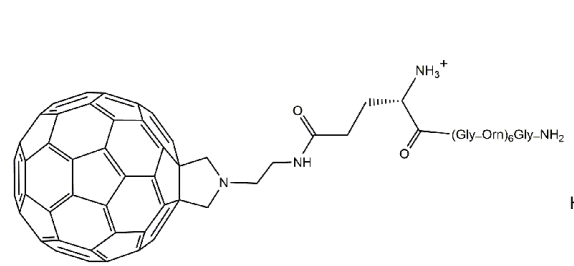

D

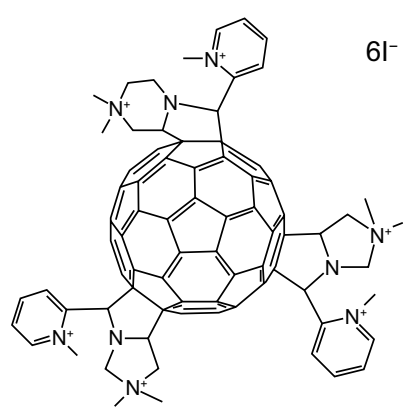

B

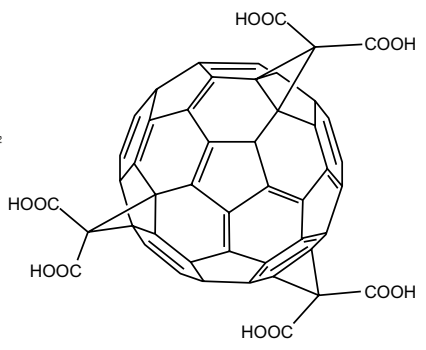

$\mathbf{E}$

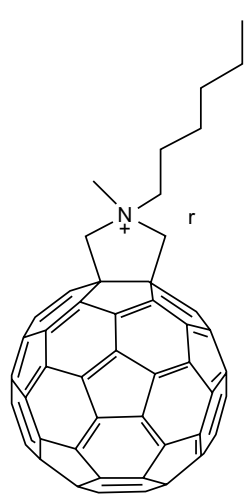

C

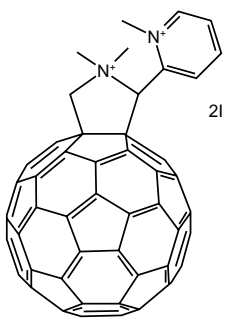

$\mathbf{F}$

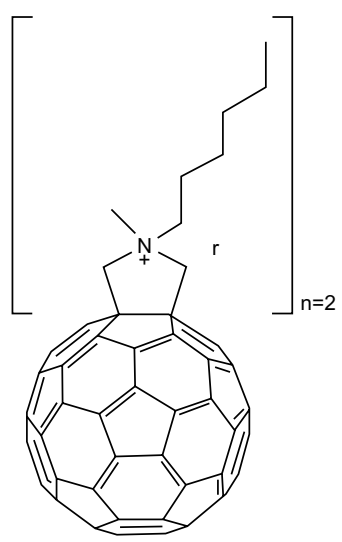

Figure 5 Chemical structures of antimicrobial fullerene derivatives 19-24. Notes: (A) 19; (B) 20; (C) 21; (D) 22; (E) 23; (F) 24.

fullerene with N-Fmoc-L-glutamic acid alpha-tert-butyl ester. ${ }^{34}$ The carboxylic end of this amino acid was deprotected, resulting in peptide 19 (Figure 5A) through solid-phase peptide synthesis. The molecule proved to be highly soluble in water-based solutions and displayed antimicrobial activity against two different strains of bacteria, Staphylococcus aureus and Escherichia coli, with the minimum inhibitory concentrations of $8 \mu \mathrm{M}$ and $64 \mu \mathrm{M}$, respectively. ${ }^{34}$ In another study, several similarly structured fulleropeptides were prepared through solid-phase peptide synthesis, displaying an increased potency in treating Gram-positive bacterial strains, although the molecules displayed decreased effectiveness against Gram-negative bacteria or yeasts when compared to the parent peptide. ${ }^{33}$

Mashino et al used molecules 14 and 15 to further investigate the antimicrobial potential of fullerene derivatives..$^{35}$ Their research suggests that inhibition of bacterial growth might actually be due to interaction of fullerene molecules in the cellular energy metabolism chain rather than the physical interruption of the cellular membrane. The study also suggests that high concentrations of fullerenes may increase the uptake of $\mathrm{O}_{2}$, ultimately causing an increase in its conversion to $\mathrm{H}_{2} \mathrm{O}_{2}$ and possibly contributing to the inhibition of the respiratory chain. ${ }^{35}$

Tsao et al studied the biological effects of a carboxyfullerene derivative, 20 (Figure 5B), on twenty different bacterial strains. ${ }^{36}$ They found that Gram-positive species were inhibited by 20 at $50 \mathrm{mg} / \mathrm{L}$, but the Gram-negative strains were not inhibited by the molecule, even at levels as high as $500 \mathrm{mg} / \mathrm{L}$. It was also found that the bactericidal potency depended on the ability of the compound to insert into microbial cell walls, as well as interactions between the compound and cellular walls of either Gram-positive or Gram-negative bacteria. The integration of the carboxyfullerene 20 into the cell wall was detected using electron microscopy and anti-carboxyfullerene antibodies, suggesting that the action of the carboxyfullerene resulted through its insertion into the cell wall and destruction caused to the membrane's integrity. ${ }^{36}$ In addition, the group discovered that 20 and its isomer decreased the permeability of the blood-brain barrier (BBB) at specific environmental conditions to the $E$. coli bacteria responsible for causing meningitis. It appeared that, during the late phase of BBB permeability, cytokines released by neutrophils, tumor necrosis factor- $\alpha$ and interleukin- $1 \beta$ specifically, 
were implicated in causing changes in $\mathrm{BBB}$ permeability and were ultimately inhibited by carboxyfullerenes..$^{37,38}$

Additionally, the quinazolin-fullerene conjugate 18 was reported to have an inhibitory potential of $98.83 \%$ at a minimal inhibitory concentration of $1.562 \mu \mathrm{g} / \mathrm{mL}$ when treating $M$. tuberculosis. ${ }^{31}$ This was an important finding, since the current first-line treatment, composed of isoniazid and rifampicin, was found to be only slightly more effective, with an inhibitory capacity of $99 \%$. The group concluded that the fullerene moiety contributed to the increased permeability of quinazolin through interaction and destruction of the bacterial cellular envelope. They further postulated that utilizing such characteristics could lead to shorter durations of anti-tuberculosis therapies. ${ }^{31,39}$ Fullerenes have been investigated as adjuncts to photodynamic therapy treatments due to their photostability at rest and ease of excitability in both the ultraviolet and visible light spectrums. Huang et al showed this utilizing cationic fullerenes 21-24 (Figure $5 \mathrm{C}-\mathrm{F}$ ) as antimicrobial agents against $E$. coli, S. aureus, and Pseudomonas aeruginosa, although variances existed between efficacies among the three. ${ }^{40}$ In another study regarding quantitative structure-activity relationships, Mizuno et al found that the most important determinant of effectiveness was an increased number of quaternary cationic groups, widely dispersed around the fullerene cage in order to minimize aggregation. ${ }^{41}$

\section{Immunological properties}

Vaccination is the process of stimulating immunity through the process of administering antigenic material with the goal of preventing or ameliorating future infections. This material can be living, attenuated, or killed, or be composed of specific antigenic portions of a pathogen or its toxins. With the goal of bolstering the immune response, fullerenes were investigated as immunologic substrates due to their polygonal configurations and their composition of solely carbon atoms.

Chen et al prepared a series of fullerene-peptide conjugates by coupling fullerene derivative 25 (Figure 6A) to bovine thyroglobulin, bovine and rabbit serum albumin, and L-Lys homotripeptides and homopentapeptides. The enzymelinked immunosorbent assay (ELISA) results showed that the presence of fullerenes did not prevent intracellular processing and subsequent peptide presentation to T-cells. ${ }^{42}$ Furthermore, Chen et al discovered that a subset of the $\mathrm{C}_{60}$ antibodies developed cross-reactivity to $\mathrm{C}_{70}$ molecules. ${ }^{42}$ This presented an interesting conjugate to be used in the future development
A
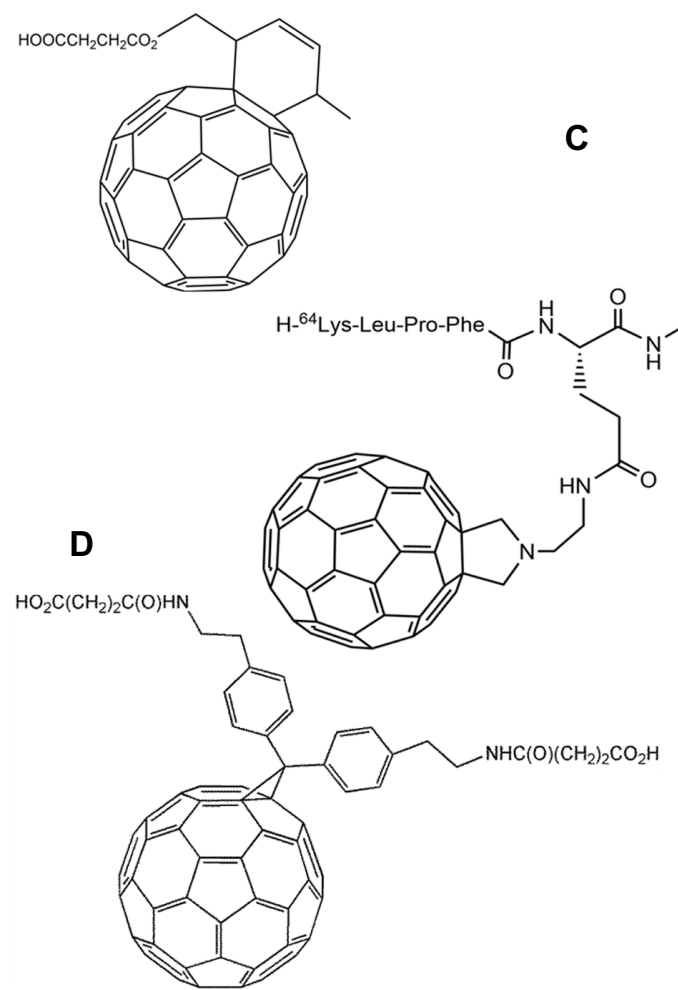

C

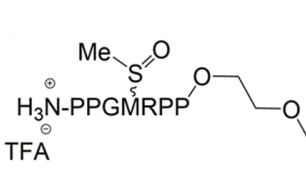

B

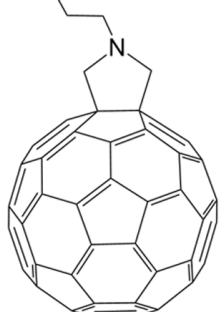

E

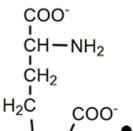

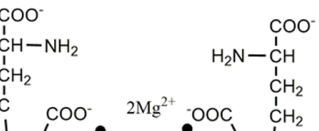

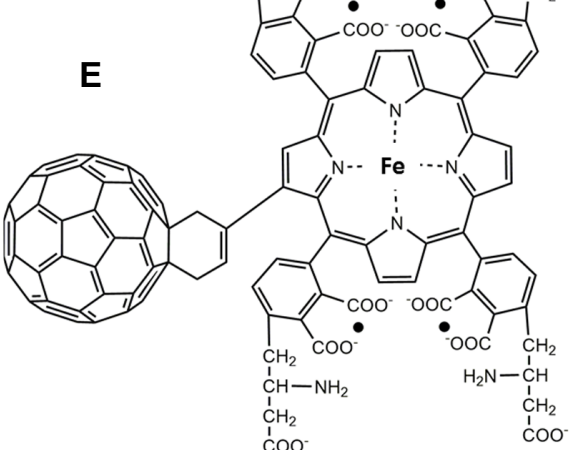

Figure 6 Chemical structures of fullerene derivatives 25-29 with immunological or membranotropic properties.

Notes: (A) 25; (B) 26; (C) 27; (D) 28; (E) 29.

Abbreviations: Me, methyl group; TFA, trifluoroacetic acid; PPGMRPP, Pro-Pro-Gly-Met-Arg-Pro-Pro. 
of vaccines. In another study, Tkach et al found that graphene oxide impaired the stimulatory potential of murine dendritic cells and decreased the activity of immunoproteasome subunits required for processing antigens; however, fullerenes internalized by murine dendritic cells stimulated the major histocompatibility complex class I-restricted T-cell response. ${ }^{43}$ It appears that the hydrophobicity of the fullerene skeleton, its curvature, the possibility of having $\pi-\pi$ stacking interactions, and an induced fit mechanism might play a role in the fullerene binding process and its ability to stimulate an immune response. ${ }^{43}$

Toniolo et al described the synthesis and detailed the characterization of the first water-soluble fullerene-peptide conjugate $13 .^{29}$ The fullerene derivative bound to a cellular receptor (the surface glycoprotein of CD4) ${ }^{44}$ of the C-terminal pentapeptide sequence of peptide $\mathrm{T}$ and, consequently, stimulated the migration of monocytes. The results indicated that peptide $\mathrm{T}$ (4-8) was a potent agonist of human monocyte chemotaxis through stimulation of the CD4/T4 receptor. In contrast, 13 exhibited high chemotactic properties. ${ }^{29}$ Furthermore, in a study performed by Marastoni et al, it was found that the $\alpha$-amino function of peptide T (4-8) is not necessary for interaction between the peptide T (4-8) and the CD4 receptor. ${ }^{45}$

A proline-rich fullerene-peptide 26 (Figure 6B), synthesized by Sofou et al, also conferred antigenic properties, as shown by ELISA. ${ }^{46}$ It was composed of a solubilizing appendage (ethylene glycol chain) covalently attached between the fullerene moiety and a heptapeptide, namely H-PPGMRPP$\mathrm{OH}$, which was found in sera of patients with autoimmune diseases such as systemic lupus erythematosus or mixed connective tissue disease. It also appeared, in other studies, that conformation greatly guided the recognition process, as demonstrated by the fact that the amide form converted from the C-terminal carboxylate group of the parent peptide reduced anti-Ro/La recognition. ${ }^{47,48}$

Bianco et al described a fulleropeptide 27 (Figure 6C) which derived from the nucleosomal histone (H3) protein attached to a L-fulleropyrrolidino-glutamic acid residue. ${ }^{49}$ Molecular modeling research suggested that this peptide analog conserved the same binding capacity to major histocompatibility complex molecules as the parent peptide; however, further studies are required to verify whether it stimulates or inhibits T-cell responses. These successful preparations are certainly encouraging in the effort to design and develop biologically active fulleropeptides that may help increase the induction of immunity.

In addition, Bunz et al investigated the effects of fullerene-based particles on the innate and adaptive immune system. ${ }^{50}$ They showed that both polyhydroxy- $\mathrm{C}_{60}$ and $\mathrm{N}$-ethyl-polyamino- $\mathrm{C}_{60}$ failed to increase reactivity in T-lymphocytes, but significantly enhanced the release of interleukin-6 and CD69 expression by CD56 positive natural killer cells. These results indicate that fullerenes did not affect T-cell reactivity but might activate cells of the innate immune system. ${ }^{50}$

\section{Membranotropic properties}

One of the most important aspects of an effective fullerene product is its ability to penetrate biological membranes in order to be transported to specific intracellular targets. Additionally, the lipophilic nature of amino acids and peptides is a great advantage for any fullerene preparation. Due to its analogy to clathrin-coated vesicles, fullerene cages may be able to play a fundamental role during the process of endocytosis as well.

Using potential-sensitive probes, Andreev et al found that water-soluble amino acid derivatives of fullerene $\mathrm{C}_{60}$, such as $\mathrm{C}_{60}-$ Pro, $\mathrm{C}_{60}-\mathrm{Asp}$, and $\mathrm{C}_{60}-\mathrm{Arg}$, could be transported across biological membranes as liophilic ions, thus causing depolarization of the membranes. ${ }^{51}$ Kotelnikova et al reported that a $\mathrm{C}_{60}{ }^{-}$ Ala and $\mathrm{C}_{60}$-Ala-Ala dipeptide could be used in the analysis of membranotropic properties of soluble fullerene derivatives. ${ }^{52}$ What they discovered was that both compounds were able to penetrate the lipid bilayer and enter the liposome. Most notable was the fact that this was accomplished without changing its structure or causing any membrane disruption. Moreover, it was shown that these derivatives were able to transport bivalent metal ions across the transmembrane. ${ }^{52}$ Later, in another research article, Kotelnikova et al found that stereoisomers of the amino acid derivatives of fullerenes selectively penetrated the phospholipid membrane. This was discussed in comparison to D- or L-isomers' abilities to penetrate the phosphatidylcholine membranes and enter the liposome's interior. ${ }^{53}$

A complete, in vivo, biopharmaceutical study was carried out by Rajagopalan et al, who utilized intravenous administration of a bis-monosuccinimide derivative, $p, p^{\prime}$-bis(2aminoethyl)-diphenyl- $\mathrm{C}_{60}, 28$ (Figure 6D). ${ }^{6}$ Derivative 28 displayed a higher affinity to tissues rather than a tendency to interact with the cellular membranes or other lipid-based structures. However, despite its promise, the study yielded significant toxicity to rats at a dose of $25 \mathrm{mg} / \mathrm{kg}$. ${ }^{6}$

In addition, Rouse et al have confirmed that an aqueous solution of a fullerene-substituted phenylalanine derivative enabled a nuclear localization peptide sequence (Baa-Lys[FITC]-NLS) to penetrate intact skin, as well as the ability to increase the rate of diffusion with the use of 
mechanical stressors. ${ }^{54}$ These results are relevant for future assessments of nanoparticles and their safety in the laboratory environment. Repetitive motion and mechanical stressors should also be taken into account in order to account for factors that could increase the likelihood of nanoparticle exposure during the manufacturing or consuming process.
The membranotropic characteristics of fullerenes also have profound implications in the development of various cationic two-handed aminofullerenes for drug delivery, particularly in the field of gene delivery ${ }^{55-57}$ or peptide transport. ${ }^{11,58}$ It was concluded that fullerene amino acids and fullerenepeptide play important roles in providing safe, hydrophobic

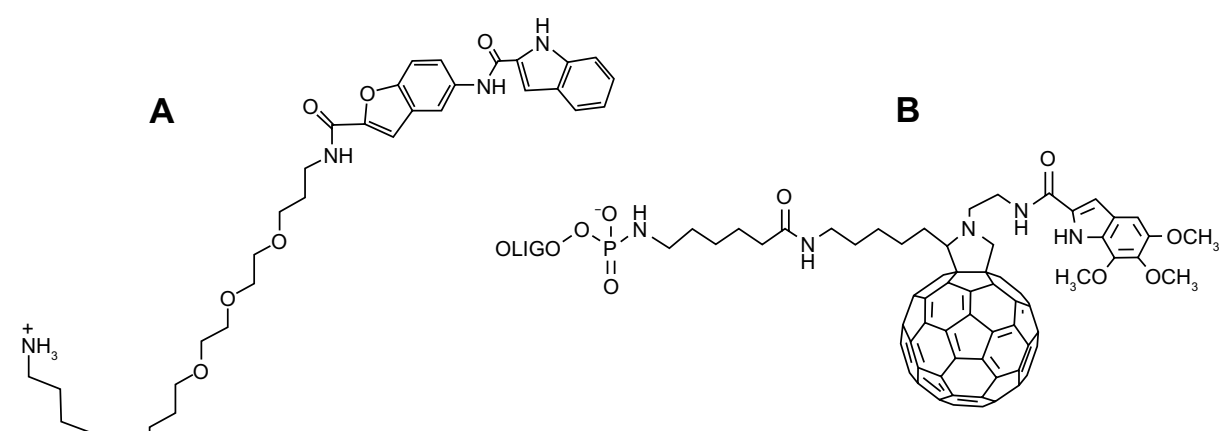

\section{OLIGO $=5^{\prime}-T T T-T C^{*} T-T T T-C^{*} C^{*} C^{*}-C^{*} C^{*} C^{*}-T-3^{\prime}$} $C^{*}=$ Methylated cytosine
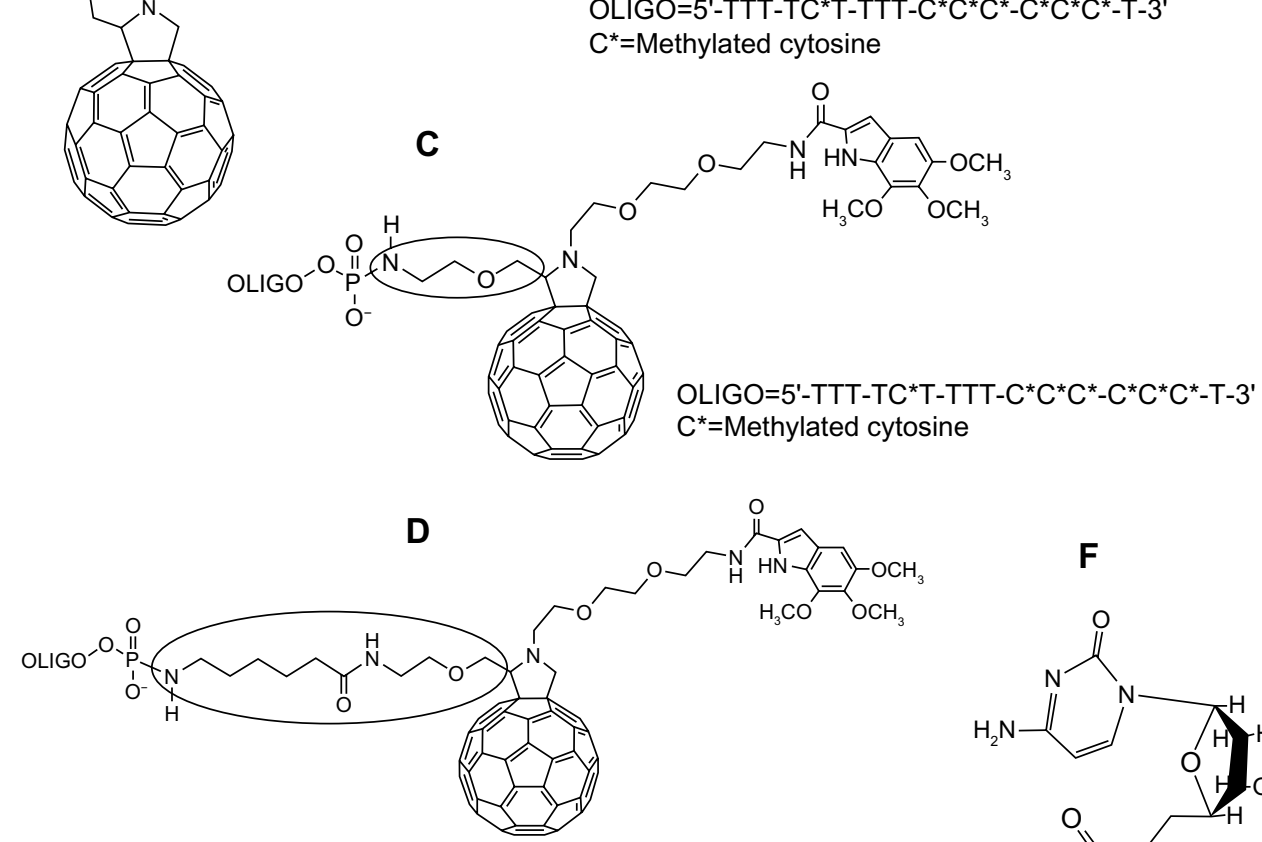

OLIGO $=5^{\prime}-T T T-T C^{*} T-T T T-C^{*} C^{*} C^{*}-C^{*} C^{*} C^{*}-T-3^{\prime}$ $\mathrm{C}^{*}=$ Methylated cytosine

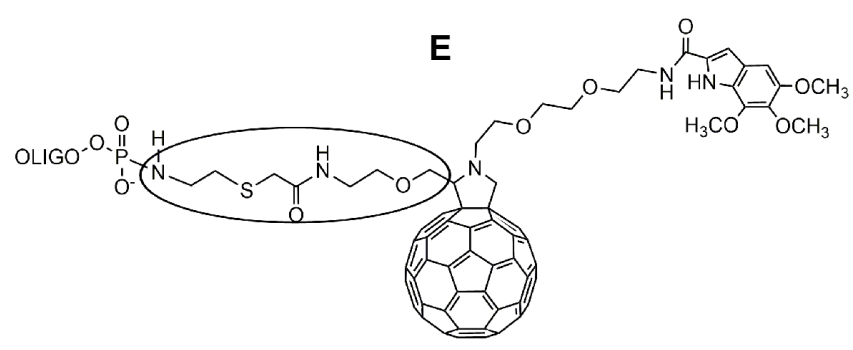

OLIGO $=5$-TTT-TC*T-TTT-C ${ }^{*} \mathrm{C}^{*} \mathrm{C}^{*}-\mathrm{C}^{*} \mathrm{C}^{*} \mathrm{C}^{*}$-T-3 $\mathrm{C}^{*}=$ Methylated Cytosine

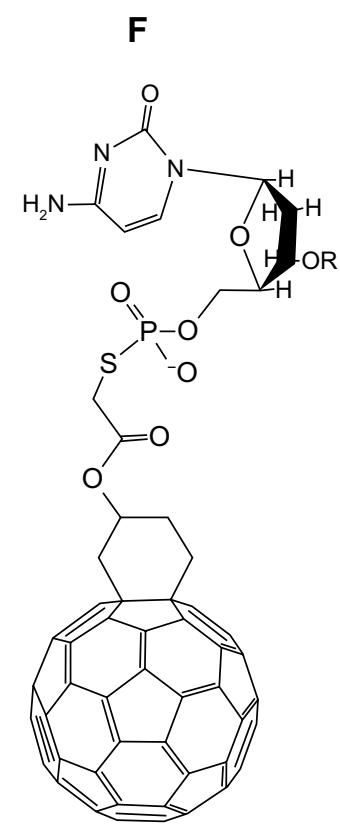

$\mathrm{R}=5$ ' tgccatcctgcgtctggacctg ' 3

Figure 7 Chemical structures of DNA-binding fullerene derivatives 30 and fullerene-oligonucleotide conjugates $3 I-35$.

Notes: (A) 30; (B) 31; (C) 32; (D) 33; (E) 34; (F) 35.

Abbreviation: OLIGO, oligonucleotide. 
transportation of gene sequences and peptides while simultaneously preventing enzymatic degradation. Further details on fullerenes for drug delivery can be found in a recent review article by Partha and Conyers. ${ }^{59}$

Two previous studies have suggested utilizing the membranotropic characteristics of fullerenes to treat hypoxia-induced mitochondrial dysfunction in mammalian heart myocytes. In one study, Amirshahi et al discovered that a fullerene-based porphyrin 29 (Figure 6E) only released paramagnetic cations in response to hypoxia-induced acidic shift due to their membranotropic cationic characteristics. ${ }^{60}$ Shetab Boushehri et al further found that, through the delivery of magnesium to doxorubicin-induced damaged heart muscle, 29 was able to stimulate $80 \%$ of recovery within damaged myocytes. ${ }^{61}$

\section{DNA-binding fullerene derivatives and fullerene-containing oligonucleotides}

The photochemical properties of fullerenes have been widely studied, using DNA photocleavage models, due to their ability to oxidize guanosine-containing sites with consequential DNA breaks. Two possible mechanisms have been suggested for the interaction between fullerenes and DNA: direct electron transfer and formation of cytotoxic singlet oxygen species. ${ }^{62,63}$
With the goal of gaining better knowledge of these mechanisms, conjugates between $\mathrm{C}_{60}$ and nucleic acidspecific agents (acridine, netropsin, and complementary oligonucleotides) have been reported. Da Ros et al synthesized a fulleropyrrolidine derivative 30 (Figure 7A), containing a dimer minor groove binder (MGB), and the MGB was demonstrated to play a strong role in enhancing the DNA photocleavage function of the molecule when compared to its analogs lacking the MGB. ${ }^{64}$ This was further supported through the analysis of duplex or triplex stability. Despite the low degree of cleavage selectivity at specific G sites, the MGB's affinity to specific adenosine/ thymidine sequences was not sufficient to induce selective DNA scission. ${ }^{64}$

Further development of research targeted the efficiency of photocleavage found in some fullerene conjugates. This effort was mainly accomplished through the stabilization of the duplex and triplex structures, and increasing their sequence selectivity. Again, Pergamin et a ${ }^{65}$ and Da Ros et $\mathrm{al}^{66}$ succeeded in the synthesis and molecular modeling of several fullerene-5,6,7-trimethoxyindole-oligonucleotide conjugates 31-34 (Figure 7B-E) as possible probes for studying photochemical reactions in DNA triple helices. It can be further deduced that DNA recognition and interaction, and even the charge on the fullerene spheres themselves, all
A

B

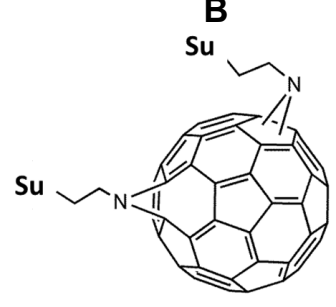

D

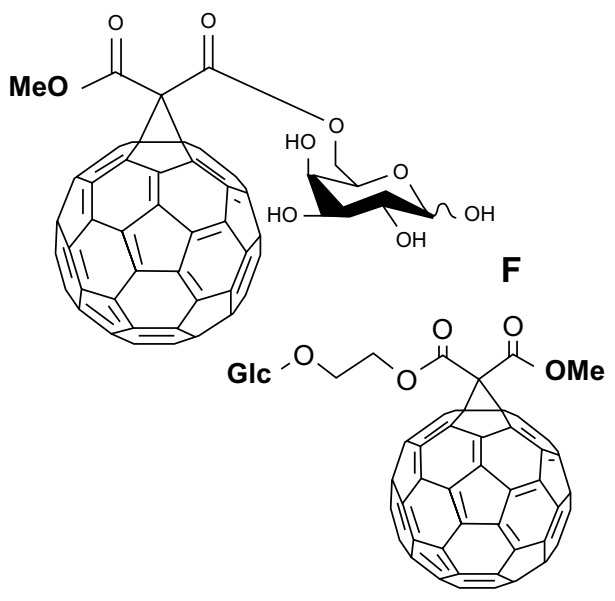

C

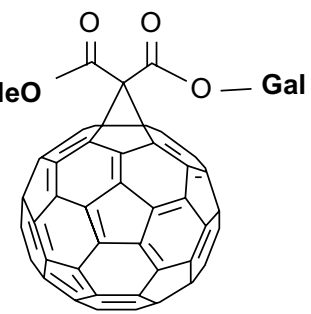<smiles>CC(C)(C(=O)OCl)C(=O)O[Hg]</smiles>

G

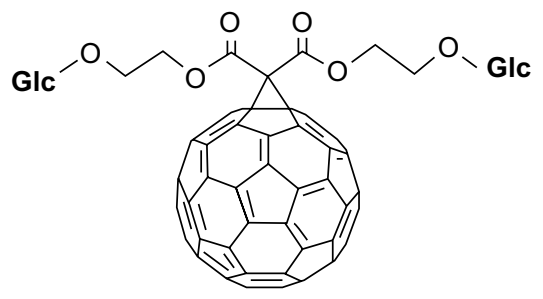

Figure 8 Chemical structures of fullerene-sugar conjugates 36-42.

Notes: (A) 36; (B) 37; (C) 38; (D) 39; (E) 40; (F) 4I; (G) 42.

Abbreviations: Su, Sugar; Gal, Galactose; Glc, Glucose; Me, Methyl group. 
related closely to the distances between oligonucleotides, $\mathrm{C}_{60}$ molecules, and the trimethoxyindole moieties. ${ }^{65,66}$

Another notable compound, synthesized by Yang et al, was a fullerene-oligonucleotide conjugate 35 (Figure 7F) containing a sequence complementary to a specific region of the $\beta$-actin cDNA. ${ }^{25}$ It was found to have great therapeutic potential, as it not only inhibited Taq DNA polymerase and the cDNA template when added to the polymerase chain reaction, but also inhibited the activity of exonuclease I. By testing the effects of two ROS scavengers, a singlet oxygen scavenger, sodium azide, and a hydroxyl radical scavenger mannitol, the inhibitory effects were significantly reduced, indicating a possible ROS-related mechanism. ${ }^{25}$ The fullerene-oligonucleotide conjugates, along with the multifunctionalized cationic fullerene adducts that were able to bind DNA, ${ }^{67,68}$ add further support for the use of fullerenes in gene therapy.

\section{Fullerene-containing sugars}

Photodynamic therapy is an effective cancer treatment technique in which porphyrins and other related macromolecules are used as photosensitizers. ${ }^{64}$ Many photosensitizers are usually composed of hydrophobic aromatic compounds, and a lot of attempts have been made to improve their solubility. Attachment of sugar moieties to chromophores is a very attractive technique, not only because of improvements in water solubility, but because carbohydrates play an important role in many cell-cell interactions. ${ }^{69-72}$

Mikata et al reported two photosensitizing, phototoxic, sugar-dependent carbohydrate-pendant fullerene derivatives, 36 (Figure 8A) and 37 (Figure 8B), describing the molecules' ability to produce singlet oxygen radicals. ${ }^{73}$ The molecule was also found to have some contribution to the photosensitizing capability of the fullerene compound itself. Despite this discovery, D-xylose and maltose derivatives appear to be less phototoxic under laser irradiation $(355 \mathrm{~nm})$ despite similar amounts of singlet oxygen radicals produced during in vitro studies. This might be due to the difference in the amount of photosensitizers incorporated. ${ }^{73}$

$\mathrm{C}_{60}$-sugar derivatives 38-42 (Figure $8 \mathrm{C}-\mathrm{G}$ ), with one or two units of D-galactose or D-glucose, were described by Enes et al, who showed that the singlet oxygen quantum yields of these derivatives dissolved in toluene and benzonitrile were closely unified to the sugar moiety found in these molecules. ${ }^{74}$

A bis( $\beta$-cyclodextrins)- $\mathrm{C}_{60} 43$ (Figure 9A) was synthesized by Filippone et al and described as highly soluble in cold water and displaying a negative solubility coefficient along with a suitable partition coefficient when combined with octanol and water. ${ }^{75}$ Liu et al used a "sandwich complexation" model for
A

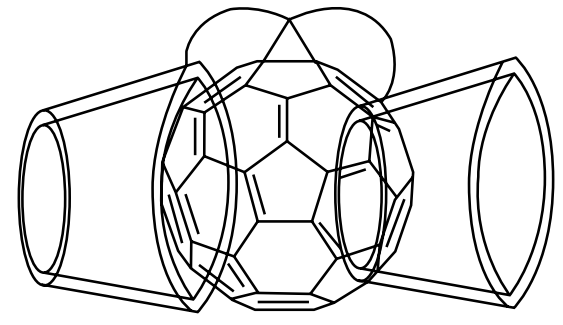

B

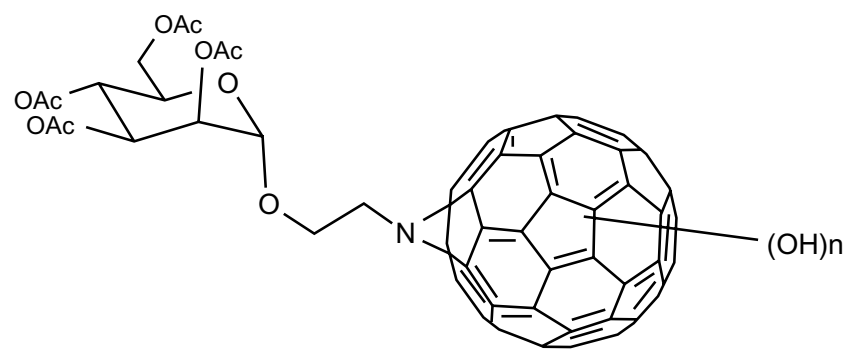

C

D

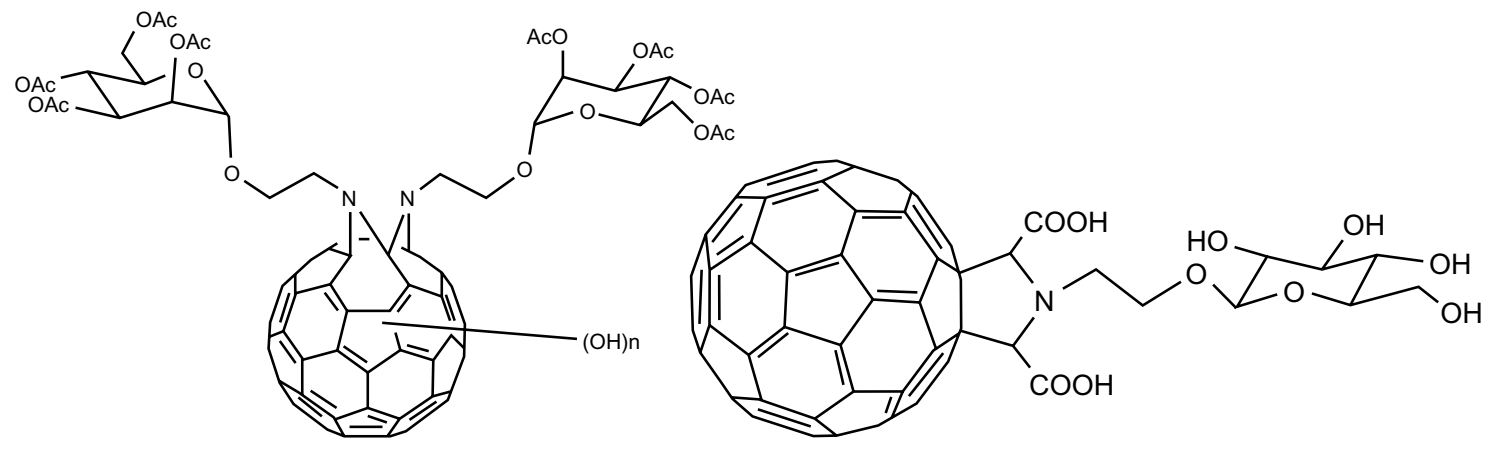

Figure 9 Chemical structures of fullerene-sugar conjugates 43-46.

Notes: (A) 43; (B) 44; (C) 45; (D) 46.

Abbreviation: Ac, Acetyl. 
cooperative binding of 43 to specific substrates by detection with ultraviolet-vis, Fourier transform infrared spectroscopy, nuclear magnetic resonance, and fluorescence and circular dichroism spectroscopy. ${ }^{76}$ It was shown that binding characteristics of 43 due to the presence of the $\beta$-cyclodextrin cavity contributed to its DNA-cleavage properties through the utilization of a singlet oxygen mechanism. ${ }^{76}$ In a more recent study, conjugation of cyclodextrin with fullerene structures displayed substantial inhibitors to the entry of the hepatitis $\mathrm{C}$ virus across membranes. ${ }^{77}$

It is known that sugar moieties have important biological functions in cellular recognition, transport, and adhesion which may provide such conjugates with novel properties. Biological evaluations of fullerenols carrying mono- and bis- $\alpha$-D-mannosyl linkages performed by Kato et al further elaborated this point. ${ }^{78}$ In their study, $\alpha$-D-mannosyl fullerenols 44 (Figure 9B) and 45 (Figure 9C) were prepared via a $[3+2]$-cycloaddition reaction between 2-azidoethyl $\alpha$-Dmannoside and $\mathrm{C}_{60}$, followed by polyhydroxylation with aqueous $\mathrm{NaOH}$. It was found that mannosyl linkage of fullerenol reduced adhesion to $\beta$-D-galactopyranoside-specific lectins, but increased the affinity to $\alpha$-D-mannose-specific lectins when compared to fullerenol parents. Furthermore, the activity of these conjugates in stimulating erythrocyte aggregation was notably decreased. ${ }^{78}$

Additionally, a recent paper published by Tanimoto et al demonstrated the fact that a fullerene-sugar hybrid 46
(Figure 9D) was a good candidate for phototherapy in the inhibition of the HIV-1 protease protein and inhibition of HIV in living cells. ${ }^{79}$ The hybrid showed promise as a target for phototherapy in the effort to effectively inhibit HIV-1 protease; however, the group did acknowledge limitations with applying such a compound in vivo, as live cells showed decreased uptake of the compound when compared to in vitro studies. ${ }^{79}$

\section{Fullerene-containing esters}

Schergna et al synthesized a group of fullerene esters 47 (Figure 10A) to investigate the enzymatic modification of fullerene derivatives. ${ }^{80}$ Research on these fullerene-based esters indicated that possible factors influencing the effect of enzymatic interactions were dependent on the distances of the reaction center from the spheroid and the steric hindrance of the ester groups involved. Reaction rates were inversely related to the distances of the functional groups that interacted with the enzyme's active site and the fullerene's spheroidal shape. Moreover, the bulkiness of the ester groups further prevented the reactions from occurring at high rates. ${ }^{80} \mathrm{It}$ is of great importance to examine if any correlation exists between the unique activities of lipase B from Candida antarctica towards fullerene derivatives, and verifying the link that is involved in this mechanism.

Peng et al recently reported the synthesis of a fullerene end-capped poly(caprolactone) and the enzymatic behavior of
A
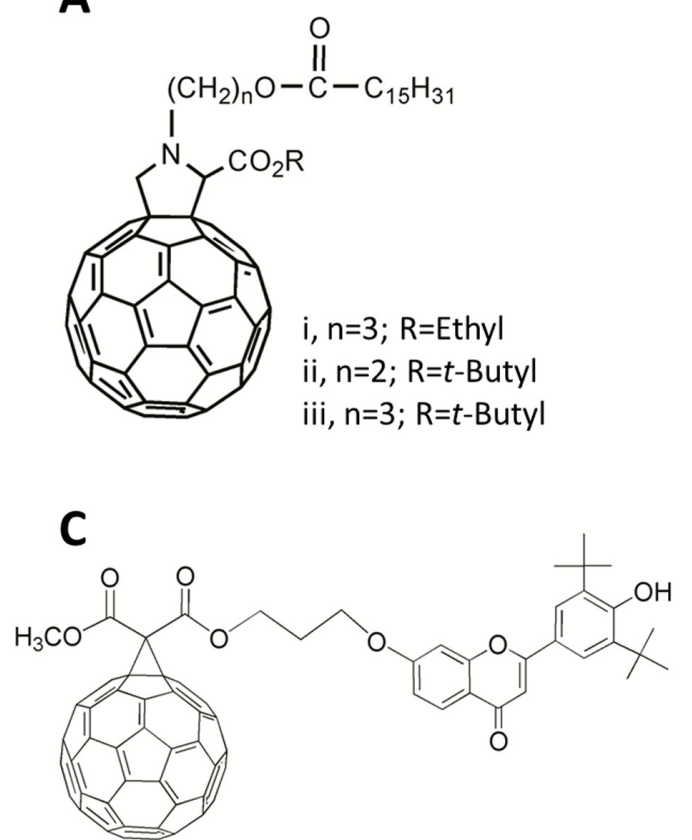

B

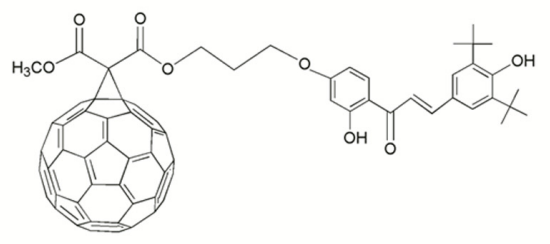

Figure 10 Chemical structures of fullerene-containing esters 47-50. Notes: (A) 47; (B) 48; (C) 49; (D) 50. 
lipase AK against this fullerene ester. ${ }^{81}$ Using $\mathrm{N}$-substituted 3,4-fulleropyrrolidine with an active hydroxyl group as an initiator, polymerization of epsilon-caprolactone was performed via ring-opening polymerization. The data indicated that the introduction of fullerenes decreased the enzymatic reaction of lipase toward poly(caprolactone) ${ }^{81}$

It is worth noting that the synthesis of fullerene-flavonoid conjugates, including $\mathrm{C}_{60}$-chalcone 48 (Figure 10B), $\mathrm{C}_{60}{ }^{-}$ flavone 49 (Figure 10C), and $\mathrm{C}_{60}$-flavanone 50 (Figure 10D) and their antioxidant abilities have also been reported by Enes et al, who concluded that these conjugates might be promising leads for future broad-spectrum radical scavengers. ${ }^{82}$ Furthermore, these conjugates are advantageous over flavonoids alone due to the traits of fullerenes described above, such as the adaption to active sites of enzymes and transportation across cell membranes. ${ }^{82}$

Finally, Liu et al described the synthesis and bioactivity of a specific fullerene-steroid conjugate, $\mathrm{C}_{60}$-dexamethasone, in mice. ${ }^{83,84}$ When compared to dexamethasone, $\mathrm{C}_{60}$-dexamethasone retained its antiinflammatory activity, while having a much lower impact on the learning function and immunosuppression. It was also shown to be an effective antioxidant as well. Furthermore, it was also found that the binding of $\mathrm{C}_{60}{ }^{-}$ dexamethasone to a glucocorticoid receptor was partially blocked in the thymocytes, causing downregulation of several apoptosis-related genes. ${ }^{85}$ These findings suggest that $\mathrm{C}_{60}$-dexamethasone might be a potential candidate for future anti-inflammatory drugs with fewer side effects compared to dexamethasone, and thus are of importance with regard to the development of novel fullerene derivatives with pharmaceutical potential. Considering that steroids are commonly used in clinical treatments and side effects of steroid treatments can frequently occur, fullerene-steroid conjugates present an interesting topic for further investigation. For example, it has been well established that the overuse of corticosteroids can cause debilitating skeletal complications such as osteonecrosis or osteoporosis. ${ }^{86}$ There is also compelling evidence that these bone disorders are closely related to the abnormal differentiation of bone marrow stem cells into adipogenic states and interrupt osteogenesis due to overloads from oxidative stresses as a result of high-dose steroid treatments. ${ }^{87}$ Therefore, we proposed that further study is needed to address whether or not certain fullerene-steroid conjugates would offer promising outcomes in the treatment of these disorders. This vacancy in the research has been addressed in a recent report showing that the fullerol molecule was capable of enhancing osteogenic activity while simultaneously inhibiting adipogenic differentiation of bone marrow stem cells in vitro. ${ }^{21}$

\section{Conclusion and future prospects}

Many advancements in fullerene research have been made since the first biological experiments involving $\mathrm{C}_{60}$ and other fullerenes. Today, the conjugation of fullerene-based biomolecules has become a primary strategy in overcoming the intrinsic hydrophobic obstacles encountered by fullerenes in an effort to utilize such molecules for biological purposes. In fact, research toward the application of fullerenes in different physicochemical and pharmacological fields is still very active, and new breakthroughs and applications are constantly being discovered.

Since ROS have been shown to play a pivotal role in aging and various degenerative diseases, fullerene conjugates with powerful antioxidative properties are promising candidates in the development of future innovative antioxidants against aging and associated diseases. Fullerenes conjugated with specific targeting peptides will undoubtedly strengthen such pursuits by facilitating the delivery of functional fullerenes to sites of interest within cells. ROS also act as important regulators of stem cell survival and differentiation, and, as such, antioxidative fullerenes will find potential applications in stem cell research and therapy. For example, fullerene polymers may be used in the fabrication of antioxidative scaffolds for tissue engineering-based treatment. In addition, nano-size fullerenes are capable of traveling across cellular membranes. Therefore, fullerenes conjugated with bioactive molecules, such as fullerene-containing antisense oligonucleotides, are anticipated to be much more advantageous over bioactive molecules alone, where fullerene may act as both an antioxidant and a carrier.

\section{Acknowledgment}

This study was supported by NIH NIAMS R21 AR062732.

\section{Disclosure}

The authors report no conflicts of interest in this work.

\section{References}

1. Kroto HW, Heath JR, O'Brien SC, Curl RF, Smalley RE. $C_{60}$ : Buckminsterfullerene. Nature. 1985;318:162-163.

2. Friedman SH, DeCamp DL, Sijbesma RP, Srdanov G, Wudl F, Kenyon GL. Inhibition of the HIV-1 protease by fullerene derivatives: model building studies and experimental verification. J Am Chem Soc. 1993;115(15):6506-6509.

3. Schinazi RF, Sijbesma R, Srdanov G, Hill CL, Wudl F. Synthesis and virucidal activity of a water-soluble, configurationally stable, derivatized C60 fullerene. Antimicrob Agents Chemother. 1993;37(8): 1707-1710. 
4. Pantarotto D, Tagmatarchis N, Bianco A, Prato M. Synthesis and biological properties of fullerene-containing amino acids and peptides. Mini Rev Med Chem. 2004;4(7):805-814.

5. Foley S, Crowley C, Smaihi M, et al. Cellular localisation of a watersoluble fullerene derivative. Biochem Bioph Res Commun. 2002;294(1): 116-119.

6. Rajagopalan P, Wudl F, Schinazi RF, Boudinot FD. Pharmacokinetics of a water-soluble fullerene in rats. Antimicrob Agents Chemother. 1996;40(10):2262-2265.

7. Bosi S, Da Ros T, Spalluto G, Prato M. Fullerene derivatives: an attractive tool for biological applications. Eur J Med Chem. 2003;38(11-12): 913-923.

8. Paradise WA, Vesper BJ, Goel A, et al. Nitric oxide: perspectives and emerging studies of a well known cytotoxin. Int J Mol Sci. 2010;11(7): 2715-2745.

9. Hur J, Pak SC, Koo BS, Jeon S. Borneol alleviates oxidative stress via upregulation of Nrf2 and Bcl-2 in SH-SY5Y cells. Pharm Biol. 2013;51(1):30-35.

10. Higashi N, Shosu T, Koga T, Niwa M, Tanigawa T. pH-responsive, selfassembling nanoparticle from a fullerene-tagged poly(L-glutamic acid) and its superoxide dismutase mimetic property. J Colloid Interface Sci. 2006;298(1):118-123.

11. Yang J, Alemany LB, Driver J, Hartgerink JD, Barron AR. Fullerenederivatized amino acids: synthesis, characterization, antioxidant properties, and solid-phase peptide synthesis. Chemistry. 2007;13(9): 2530-2545.

12. Ioannou E, Hirsch A, Elemes Y. Sulfur-containing dihydro-pyrrolo [60] fullerene derivatives via 1,3-dipolar cycloadditions of glycine imine esters to C60. Tetrahedron. 2007;63(30):7070-7076.

13. Hu Z, Guan W, Wang W, Huang L, Xing H, Zhu Z. Synthesis of beta-alanine $\mathrm{C} 60$ derivative and its protective effect on hydrogen peroxide-induced apoptosis in rat pheochromocytoma cells. Cell Biol Int. 2007;31(8):798-804.

14. Hu Z, Guan W, Wang W, Huang L, Xing H, Zhu Z. Protective effect of a novel cystine $\mathrm{C}(60)$ derivative on hydrogen peroxide-induced apoptosis in rat pheochromocytoma PC12 cells. Chem Biol Interact. 2007;167(2):135-144

15. Chen T, Li YY, Zhang JL, et al. Protective effect of C(60)-methionine derivate on lead-exposed human SH-SY5Y neuroblastoma cells. J Appl Toxicol. 2011;31(3):255-261.

16. Cusan C, Da Ros T, Spalluto G, et al. A new multi-charged C60 derivative: synthesis and biological properties. European J Org Chem. 2002;(17):2928-2934.

17. Kraszewski S, Tarek M, Ramseyer C. Uptake and translocation mechanisms of cationic amino derivatives functionalized on pristine $\mathrm{C} 60$ by lipid membranes: a molecular dynamics simulation study. ACS Nano. 2011;5(11):8571-8578.

18. Basso AS, Frenkel D, Quintana FJ, et al. Reversal of axonal loss and disability in a mouse model of progressive multiple sclerosis. J Clin Invest. 2008;118(4):1532-1543.

19. Makarova EG, Gordon RY, Podolski IY. Fullerene C60 prevents neurotoxicity induced by intrahippocampal microinjection of amyloid-beta peptide. J Nanosci Nanotechnol. 2012;12(1):119-126.

20. Fujimoto T, Ito S, Ito M, Kanazawa H, Yamaguchi S. Induction of different reactive oxygen species in the skin during various laser therapies and their inhibition by fullerene. Laser Surg Med. 2012;44(8):685-694.

21. Liu HJ, Yang XL, Zhang Y, Dighe A, Li XD, Cui QJ. Fullerol antagonizes dexamethasone-induced oxidative stress and adipogenesis while enhancing osteogenesis in a cloned bone marrow mesenchymal stem cell. J Orthop Res. 2012;30(7):1051-1057.

22. Cai X, Jia H, Liu Z, et al. Polyhydroxylated fullerene derivative C(60) $(\mathrm{OH})(24)$ prevents mitochondrial dysfunction and oxidative damage in an MPP(+)-induced cellular model of Parkinson's disease. J Neurosci Res. 2008;86(16):3622-3634.

23. Mashino T, Shimotohno K, Ikegami N, et al. Human immunodeficiency virus-reverse transcriptase inhibition and hepatitis $\mathrm{C}$ virus RNAdependent RNA polymerase inhibition activities of fullerene derivatives. Bioorg Med Chem Lett. 2005;15(4):1107-1109.
24. Meng X, Li B, Chen Z, et al. Inhibition of a thermophilic deoxyribonucleic acid polymerase by fullerene derivatives. J Enzyme Inhib Med Chem. 2007;22(3):293-296.

25. Yang X, Meng X, Li B, et al. Inhibition of in vitro amplification of targeted DNA fragment and activity of exonuclease I by a fullereneoligonucleotide conjugate. Biologicals. 2008;36(4):223-226.

26. Shang J, Ratnikova TA, Anttalainen S, Salonen E, Ke PC, Knap HT. Experimental and simulation studies of a real-time polymerase chain reaction in the presence of a fullerene derivative. Nanotechnology. 2009;20(41):415101.

27. Nedumpully Govindan P, Monticelli L, Salonen E. Mechanism of taq DNA polymerase inhibition by fullerene derivatives: insight from computer simulations. J Phys Chem B. 2012;116(35):10676-10683.

28. Maoyong S, Guibin J, Junfa Y, Hailin W. Inhibition of polymerase activity by pristine fullerene nanoparticles can be mitigated by abundant proteins. Chem Commun (Camb). 2010;46(9):1404-1406.

29. Toniolo C, Bianco A, Maggini M, et al. A bioactive fullerene peptide. J Med Chem. 1994;37(26):4558-4562.

30. Pastorin G, Marchesan S, Hoebeke J, et al. Design and activity of cationic fullerene derivatives as inhibitors of acetylcholinesterase. Org Biomol Chem. 2006;4(13):2556-2562.

31. Patel MB, Harikrishnan U, Valand NN, Modi NR, Menon SK. Novel cationic quinazolin-4(3H)-one conjugated fullerene nanoparticles as antimycobacterial and antimicrobial agents. Arch Pharm (Weinheim). 2013;346(3):210-220.

32. Bosi S, Da Ros T, Spalluto G, Balzarini J, Prato M. Synthesis and antiHIV properties of new water-soluble bis-functionalized[60]fullerene derivatives. Bioorg Med Chem Lett. 2003;13(24):4437-4440.

33. Pantarotto D, Bianco A, Pellarini F, et al. Solid-phase synthesis of fullerene-peptides. J Am Chem Soc. 2002;124(42):12543-12549.

34. Pellarini F, Pantarotto D, Da Ros T, Giangaspero A, Tossi D, Prato N. A novel [60]fullerene amino acid for use in solid-phase peptide synthesis. Org Lett. 2001;3(12):1845-1848

35. Mashino T, Usui N, Okuda K, Hirota T, Mochizuki M. Respiratory chain inhibition by fullerene derivatives: hydrogen peroxide production caused by fullerene derivatives and a respiratory chain system. Bioorg Med Chem. 2003;11(7):1433-1438.

36. Tsao N, Luh TY, Chou CK, et al. In vitro action of carboxyfullerene. J Antimicrob Chemother. 2002;49(4):641-649.

37. Tsao N, Kanakamma PP, Luh TY, Chou CK, Lei HY. Inhibition of Escherichia coli-induced meningitis by carboxyfullerence. Antimicrob Agents Chemother. 1999;43(9):2273-2277.

38. Tsao N, Wu CM, Hsu HP, et al. Inhibition of the increased permeability of blood-brain barrier in Escherichia coli-induced meningitis by carboxyfullerene. Fullerene Science and Technology. 2001;9(3): 307-320.

39. Patel MB, Kumar SP, Valand NN, Jasrai YT, Menon SK. Synthesis and biological evaluation of cationic fullerene quinazolinone conjugates and their binding mode with modeled Mycobacterium tuberculosis hypoxanthine-guanine phosphoribosyltransferase enzyme. J Mol Model. 2013;19(8):3201-3217.

40. Huang LY, Terakawa M, Zhiyentayev T, et al. Innovative cationic fullerenes as broad-spectrum light-activated antimicrobials. Nanomedicine. 2010;6(3):442-452.

41. Mizuno K, Zhiyentayev T, Huang L, et al. Antimicrobial photodynamic therapy with functionalized fullerenes: quantitative structure-activity relationships. J Nanomed Nanotechnol. 2011;2(2):1-9.

42. Chen BX, Wilson SR, Das M, Coughlin DJ, Erlanger BF. Antigenicity of fullerenes: Antibodies specific for fullerenes and their characteristics. Proc Natl Acad Sci U S A. 1998;95(18):10809-10813.

43. Tkach AV, Yanamala N, Stanley S, et al. Graphene oxide, but not fullerenes, targets immunoproteasomes and suppresses antigen presentation by dendritic cells. Small. 2013;9(9-10):1686-1690.

44. Ramsdale TE, Andrews PR, Nice EC. Verification of the interaction between peptide T and CD4 using surface-plasmon resonance. FEBS Lett. 1993;333(3):217-222.

45. Marastoni M, Salvadori S, Balboni G, et al. Structure-activityrelationships of peptide T-related pentapeptides. Arzneimittelforschung. 1989;39(8):926-928. 
46. Sofou P, Elemes Y, Panou-Pomonis E, et al. Synthesis of a proline-rich [60]fullerene peptide with potential biological activity. Tetrahedron. 2004;60(12):2823-2828.

47. Petrovas CJ, Vlachoyiannopoulos PG, Tzioufas AG, et al. A major Sm epitope anchored to sequential oligopeptide carriers is a suitable antigenic substrate to detect anti-Sm antibodies. J Immunol Methods. 1998;220(1-2):59-68.

48. Sakarellos C, Tsikaris V, Panou-Pomonis E, et al. The PPGMRPP repetitive epitope of the $\mathrm{Sm}$ autoantigen: antigenic specificity induced by conformational changes. Application of the Sequential Oligopeptide Carriers (SOCs). Letters in Peptide Science. 1997;4(4-6):447-454.

49. Bianco A, Pantarotto D, Hoebeke J, Briand JP, Prato M. Solid-phase synthesis and characterization of a novel fullerene-peptide derived from histone H3. Org Biomol Chem. 2003;1(23):4141-4143.

50. Bunz H, Plankenhorn S, Klein R. Effect of buckminsterfullerenes on cells of the innate and adaptive immune system: an in vitro study with human peripheral blood mononuclear cells. Int J Nanomedicine. 2012;7:4571-4580.

51. Andreev IM, Romanova VS, Petrukhina AO, Andreev SM. Amino-acid derivatives of fullerene $\mathrm{C}_{60}$ behave as lipophilic ions penetrating through biomembranes. Physics of the Solid State. 2002;44(4):683-685.

52. Kotelnikova RA, Kotelnikov AI, Bogdanov GN, et al. Membranotropic properties of the water soluble amino acid and peptide derivatives of fullerene C-60. FEBS Lett. 1996;389(2):111-114.

53. Kotelnikova RA, Bogdanov GN, Frog EC, et al. Nanobionics of pharmacologically active derivatives of fullerene $\mathrm{C}_{60} . J$ Nanopart Res. 2003;5(5-6):561-566.

54. Rouse JG, Yang JZ, Ryman-Rasmussen JP, Barron AR, Monteiro-Riviere NA. Effects of mechanical flexion on the penetration of fullerene amino acid-derivatized peptide nanoparticles through skin. Nano Lett. 2007;7(1):155-160.

55. Isobe H, Nakanishi W, Tomita N, Jinno S, Okayama H, Nakamura E. Nonviral gene delivery by tetraamino fullerene. Mol Pharm. 2006;3(2): 124-134.

56. Isobe H, Nakanishi W, Tomita N, Jinno S, Okayama H, Nakamura E. Gene delivery by aminofullerenes: structural requirements for efficient transfection. Chem Asian J. 2006;1(1-2):167-175.

57. Maeda-Mamiya $\mathrm{R}$, Noiri $\mathrm{E}$, Isobe $\mathrm{H}$, et al. In vivo gene delivery by cationic tetraamino fullerene. Proc Natl Acad Sci U SA. 2010;107(12): 5339-5344.

58. Yang J, Wang K, Driver J, Barron AR. The use of fullerene substituted phenylalanine amino acid as a passport for peptides through cell membranes. Org Biomol Chem. 2007;5(2):260-266.

59. Partha R, Conyers JL. Biomedical applications of functionalized fullerene-based nanomaterials. Int J Nanomedicine. 2009;4:261-275.

60. Amirshahi N, Alyautdin RN, Sarkar S, et al. Fullerene-based low toxic nanocationite particles (porphyrin adducts of cyclohexyl fullerene$\mathrm{C}(60))$ to treat hypoxia-induced mitochondrial dysfunction in mammalian heart muscle. Arch Med Res. 2008;39(6):549-559.

61. Shetab Boushehri SV, Ostad SN, Sarkar S, et al. The C60-fullerene porphyrin adducts for prevention of the doxorubicin-induced acute cardiotoxicity in rat myocardial cells. Acta Med Iran. 2010;48(5):342-350.

62. Bernstein R, Prat F, Foote CS. On the mechanism of DNA cleavage by fullerenes investigated in model systems: Electron transfer from guanosine and 8-oxo-guanosine derivatives to C-60. J Am Chem Soc. 1999;121(2):464-465.

63. Prat F, Hou CC, Foote CS. Determination of the quenching rate constants of singlet oxygen by derivatized nucleosides in nonaqueous solution. J Am Chem Soc. 1997;119(21):5051-5052.

64. Da Ros T, Spalluto G, Boutorine AS, Bensasson RV, Prato M. DNAphotocleavage agents. Curr Pharm Des. 2001;7(17):1781-1821.

65. Bergamin M, Da Ros T, Spalluto G, Boutorine A, Prato M. Synthesis of a hybrid fullerene-trimethoxyindole-oligonucleotide conjugate. Chem Commun (Camb). 2001;1:17-18.

66. Da Ros T, Bergamin M, Vazquez E, et al. Synthesis and molecular modeling studies of fullerene-5,6,7-trimethoxyindole-oligonucleotide conjugates as possible probes for study of photochemical reactions in DNA triple helices. European J Org Chem. 2002;(3):405-413.
67. Klumpp C, Lacerda L, Chaloin O, et al. Multifunctionalised cationic fullerene adducts for gene transfer: design, synthesis and DNA complexation. Chem Commun (Camb). 2007;(36):3762-3764.

68. Montellano A, Da Ros T, Bianco A, Prato M. Fullerene $\mathrm{C}_{60}$ as a multifunctional system for drug and gene delivery. Nanoscale. 2011;3(10): 4035-4041.

69. Hamazawa A, Kinoshita I, Breedlove B, et al. Meso-tetraphenylporphyrin having hexa-maltosyl and decyl chain as an amphiphilic photosensitizer toward photodynamic therapy. Chem Lett. 2002;(3):388-389.

70. Mikata Y, Onchi Y, Shibata M, et al. Synthesis and phototoxic property of tetra- and octa-glycoconjugated tetraphenylchlorins. Bioorg Med Chem Lett. 1998;8(24):3543-3548.

71. Mikata Y, Onchi Y, Tabata K, et al. Sugar-dependent photocytotoxic property of tetra- and octa-glycoconjugated tetraphenylporphyrins. Tetrahedron Lett. 1998;39(25):4505-4508.

72. Zheng G, Graham A, Shibata M, et al. Synthesis of beta-galactoseconjugated chlorins derived by enyne metathesis as galectin-specific photosensitizers for photodynamic therapy. J Org Chem. 2001;66(26): 8709-8716.

73. Mikata Y, Takagi S, Tanahashi M, et al. Detection of $1270 \mathrm{~nm}$ emission from singlet oxygen and photocytotoxic property of sugar-pendant 60 fullerenes. Bioorg Med Chem Lett. 2003;13(19):3289-3292.

74. Enes RF, Tomé AC, Cavaleiro JAS, El-Agamey A, McGarvey DJ. Synthesis and solvent dependence of the photophysical properties of [60]fullerene-sugar conjugates. Tetrahedron. 2005;61(50): 11873-11881.

75. Filippone S, Heimann F, Rassat A. A highly water-soluble 2:1 beta-cyclodextrin-fullerene conjugate. Chem Commun (Camb). 2002;(14):1508-1509.

76. Liu Y, Liang P, Chen Y, Zhao YL, Ding F, Yu A. Spectrophotometric study of fluorescence sensing and selective binding of biochemical substrates by $2,2^{\prime}$-bridged biso(beta-cyclodextrin) and its water-soluble fullerene conjugate. J Phys Chem B. 2005;109(49):23739-23744.

77. Xiao SL, Wang Q, Yu F, et al. Conjugation of cyclodextrin with fullerene as a new class of HCV entry inhibitors. Bioorg Med Chem. 2012;20(18):5616-5622.

78. Kato H, Yashiro A, Mizuno A, Nishida Y, Kobayashi K, Shinohara H. Syntheses and biological evaluations of alpha-D-mannosyl [60] fullerenols. Bioorg Med Chem Lett. 2001;11(22):2935-2939.

79. Tanimoto S, Sakai S, Kudo E, et al. Target-selective photodegradation of HIV-1 protease and inhibition of HIV-1 replication in living cells by designed fullerene-sugar hybrids. Chem Asian J. 2012;7(5):911-914.

80. Schergna S, Da Ros T, Linda P, Ebert C, Gardossi L, Prato M. Enzymatic modification of fullerene derivatives. Tetrahedron Lett. 1998;39(42): 7791-7794.

81. Peng QY, Kang F, Li JA, Yang XL. Degradation of a fullerene endcapped polycaprolactone by lipase AK. Chin Sci Bull. 2010;55(29): 3279-3282.

82. Enes RF, Farinha ASF, Tomé AC, et al. Synthesis and antioxidant activity of [60]fullerene-flavonoid conjugates. Tetrahedron. 2009;65(1):253-262.

83. Liu RL, Yin JJ, Li WX. Synthesis of glucocorticoid-C ${ }_{60}$ hybrids. Carbon. 2006;44(2):387-388.

84. Liu R, Cai X, Wang J, Li J, Huang Q, Li W. Research on the bioactivities of C60-dexamethasone. J Nanosci Nanotechnol. 2009;9(5): 3171-3176.

85. Zhang Y, Wang L, Sun Y, et al. Conjugation of dexamethasone to C60 for the design of an anti-inflammatory nanomedicine with reduced cellular apoptosis. ACS Appl Mater Interfaces. 2013;5(11): 5291-5297.

86. Powell C, Chang C, Gershwin ME. Current concepts on the pathogenesis and natural history of steroid-induced osteonecrosis. Clin Rev Allergy Immunol. 2011;41(1):102-113.

87. Manolagas SC. From estrogen-centric to aging and oxidative stress: a revised perspective of the pathogenesis of osteoporosis. Endocr Rev. 2010;31(3):266-300. 


\section{Publish your work in this journal}

The International Journal of Nanomedicine is an international, peerreviewed journal focusing on the application of nanotechnology in diagnostics, therapeutics, and drug delivery systems throughout the biomedical field. This journal is indexed on PubMed Central, MedLine, CAS, SciSearch $\AA$, Current Contents ${ }^{\circledR} /$ Clinical Medicine,

Journal Citation Reports/Science Edition, EMBase, Scopus and the Elsevier Bibliographic databases. The manuscript management system is completely online and includes a very quick and fair peer-review system, which is all easy to use. Visit http://www.dovepress.com/ testimonials.php to read real quotes from published authors.

Submit your manuscript here: http://www.dovepress.com/international-journal-of-nanomedicine-journal 